\title{
Construction, Selection and Immunogenicity of Recombinant Fowlpox Candidate Vaccine Co-expressing HIV-1 gag and gp145
}

\author{
Yilong Zhu ${ }^{1} \cdot$ Yan Guo $^{3} \cdot$ Shouwen Du${ }^{1} \cdot$ Cunxia Liu $^{1} \cdot$ Maopeng Wang ${ }^{1}$. \\ Dayong Ren ${ }^{1}$ Fei Zhao ${ }^{1}$ - Yanfang Zhang ${ }^{1}$ - Wenchao Sun ${ }^{1} \cdot$ Yiquan $\mathbf{L i}^{1}$. \\ Tingting $\mathrm{Cao}^{1} \cdot$ Yingyue Jiang $^{1} \cdot$ Bin Xing $^{1} \cdot$ Bing Bai $^{1} \cdot$ Chang $\mathrm{Li}^{1,2}$. \\ Ningyi Jin ${ }^{1,2}$
}

Received: 8 July 2016/ Accepted: 23 January 2017/Published online: 9 February 2017

(C) Association of Microbiologists of India 2017

\begin{abstract}
An HIV candidate vaccine for the Chinese population was designed by constructing a recombinant fowlpox virus expressing HIV-1 gag and HIV gp145 proteins via homologous recombination and plaque screening using enhanced green fluorescent protein $(E G F P)$ as the reporter gene. EGFP in the recombinant was then knocked out with the Cre/Loxp system yielding $\mathrm{rFPV}_{\mathrm{Hg}-\mathrm{Hp}}$, which was identified at the genomic, transcriptional and translational levels. The immunogenicity of $\mathrm{rFPV}_{\mathrm{Hg}-\mathrm{Hp}}$ was analyzed by measuring levels of HIV-specific antibodies and IFN- $\gamma$-secreting splenocytes by enzyme-linked immunosorbent assay and IFN enzyme-linked immune spot test in the BALB/c mouse model. Results showed that rFPV could not stimulate HIV-1 specific antibodies or IFN$\gamma$-secreting cells by a single immunization. Meanwhile, in the prime-boost strategy, HIV-p24 antibodies $(P<0.01)$ and IFN- $\gamma$-secreting cells $(P<0.05)$ were induced strongly by the candidate vaccine after the boost immunization. Thus, both humoral and cellular immunity could be elicited by the candidate vaccine in a prime-boost immunization
\end{abstract}

Chang Li

lichang78@163.com

Ningyi Jin

ningyij@ hotmail.com

1 Key Laboratory of Jilin Province for Zoonosis Prevention and Control, Institute of Military Veterinary, Academy of Military Medical Sciences, Changchun 130122, China

2 Jiangsu Co-innovation Center for Prevention and Control of Important Animal Infectious Diseases and Zoonoses, Yangzhou 225009, China

3 Changchun University of Traditional Chinese Medicine, Changchun 130117, China strategy. This study provides a foundation for future preclinical studies on the HIV $\mathrm{rFPV}_{\mathrm{Hg}-\mathrm{Hp}}$ candidate vaccine.

Keywords Recombinant fowlpox virus · HIV-1 gaggp145 - HIV-1-specific antibodies · HIV-1-specific IFN- $\gamma$ secreting splenocytes

\section{Introduction}

Avipoxvirus replicates strictly in the cytoplasm of infected cells and can express heterologous proteins. Although its infectious virus particles cannot be reproduced in mammals under general conditions, recombinant avipoxvirus is constructed relatively easily, and recombinant fowlpox virus ( $\mathrm{rFPV}$ ) vector-based vaccines have been applied in poultry, non-human mammals and humans [1-3]. FPV as a genetically engineered live-vector vaccine has been used for development in poultry and to protect against disease in mammals including humans.

The HIV-1 gag core protein is one of the most highly conserved viral antigens and as been targeted for the development of vaccine for diverse HIV-1 subtypes [4-6]. In natural infection, HIV-1-specific $\mathrm{CD} 8^{+} \mathrm{T}$ cells have been shown to play an important role in controlling HIV1 viremia over time [7-9]. Thus, HIV-1 gag is widely preferred as an antigen in HIV vaccine development [9-11]. The target of HIV-1 broadly neutralizing monoclonal antibodies is the envelope (Env) glycoprotein, which is a major viral neutralization antigen that has been shown to protect against HIV-1 effectively in animal models. However, the expression level of wild-type HIV1 Env gene was low, and the cytotoxicity of primary Env glycoprotein gp160 was high [12]. Therefore, gp145 was constructed by truncating gp160 with structural 
modifications and codon optimization in order to retain conserved epitopes yet reduce the toxicity of the membrane protein [13].

The Chinese FPV vaccine strain FPV282E4 and FPV shuttle vector pT3eGFP150 were constructed previously in our laboratory as a recombinant system [14]. Here, the recombinant $\mathrm{rFPV}_{\mathrm{Hg} \text {-Hp-EGFP }}$ expressing HIV-1 gag, HIV gp145 and EGFP as the reporter was constructed and selected by fluorescent plaque screening. The EGFP gene of $\mathrm{rFPV}_{\mathrm{Hg}-\mathrm{Hp}-\mathrm{EGFP}}$ was then knocked out by using the Cre/ Loxp system. The resulting $\mathrm{rFPV}_{\mathrm{Hg}-\mathrm{Hp}}$ was verified and identified at the genomic, transcriptional and translational levels. The immunogenicity of $\mathrm{rFPV}_{\mathrm{Hg}-\mathrm{Hp}}$ also was investigated through measuring the levels of HIV-1-specific antibodies and IFN- $\gamma$-secreting cells in a BALB/c mouse model.

\section{Materials and Methods}

\section{Plasmids, Virus and Cells}

The rFPV shuttle vector plasmid pT3eGFP150, pVR-HIV1 gag containing the full-length gag gene and pVR-HIV gp145 were kindly provided by Xia Feng at the Chinese Center for Disease Control and Prevention.

The plasmid pVAX-Cre was constructed previously in our laboratory, the 282E4 strain of FPV (FPV282E4), an attenuated vaccine, were produced by the Animal Pharmaceutical Factory of Nanjing (Nanjing, China). Human embryonic kidney (HEK293) cells were cultured in DMEM with $10 \%$ fetal bovine serum and $1 \%$ penicillin $(100 \mathrm{U} /$ $\mathrm{mL}) /$ streptomycin $(100 \mu \mathrm{g} / \mathrm{mL})$ solution. Eight-day-old specific-pathogen free (SPF) chickens which were used to prepare the chick embryo fibroblast (CEF) cells were purchased from (Meiliyaweitong Experimental Animal Technology Co. Ltd, Beijing, China).

\section{Construction of Plasmids Expressing HIV-1 gag and gp145 Genes}

The shuttle vector pT3eGFP150 (4816 bp), containing the left (TKL) and right (TKR) halves of the $T K$ gene, a double-gene expression cassette and EGFP gene, was used as a skeleton. The $1.5 \mathrm{~kb}$ HIV-1 gag gene was cloned into the multiple cloning site (MCS) 1 of pT3eGFP150 by standard molecular cloning techniques, forming pT3eGFP150-HIV gag. Thereafter, the $2.1 \mathrm{~kb}$ HIV-1 gp145 gene was inserted into MCS2 of pT3eGFP150-HIV gag in the same way, forming pT3eGFP150-HIV gag-HIV gp145 (pT3eGFP-Hg-Hp).

\section{Homologous Recombination, Screening and Acquisition of Recombinant Virus}

CEF cells were infected with FPV282E4 at the multiplicity of infection (MOI) of 1 at $37{ }^{\circ} \mathrm{C}$ with $5 \% \mathrm{CO}_{2}$ for $2 \mathrm{~h}$. The cells were then transfected with $1 \mu \mathrm{g}$ plasmid pT3eGFP150-Hg-Hp using a QIAGEN reagent (Germany) following the manufacturer's instructions. Transfected cells were cultured at $37{ }^{\circ} \mathrm{C}$ with $5 \% \mathrm{CO}_{2}$ for $72 \mathrm{~h}$, and green fluorescent plaques were picked out under a fluorescence microscope. The virus was released from cells by ultrasonication and used for further infection to select for the rFPV, which was named $\mathrm{rFPV}_{\mathrm{Hg}-\mathrm{Hp} \text {-EGFP }}$ after selection by plaque screening. The plasmid $\mathrm{pVAX}-\mathrm{Cre}$ and $\mathrm{rFPV}_{\mathrm{Hg}}$ Hp-EGFP were co-transfected into CEF cells at $80 \%$ confluency with QIAGEN reagent. The plaques without green fluorescence were picked out under a fluorescence microscope, amplified and then identified.

\section{Identification of rFPV}

The genomic DNA (gDNA) and total cellular RNA of

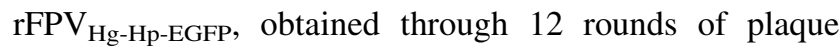
screening, were extracted using the SDS-Protease K-Phenol method and the Trizol method (Life Technologies), respectively, and used as PCR templates for the amplification of HIV-1 gag, HIV gp145, FPV-P4b and FPV-TK. The gDNA and RNA of $\mathrm{rFPV}_{\mathrm{Hg}-\mathrm{Hp}}$ were obtained in the same way and used as PCR templates for the amplification of HIV-1 gag, HIV gp145, EGFP and FPV-TK. The primers are shown in Table 1 . As the $T K$ gene is a common insertion site of VAVC and used as a recombinant site for FPV and other avipoxviruses [15, 16], it is typically used as a selection marker for acquisition of rFPV. The $P 4 b$ gene encoding the virion nucleoprotein $(75 \mathrm{kDa})$, which is widely found in FPV, was used for identification of FPV [17].

\section{Western Blot}

A CEF cell layer was infected with the recombinant virus $\mathrm{rFPV}_{\mathrm{Hg} \text {-Hp-EGFP }}$ at the MOI of 1 and cultured at $37{ }^{\circ} \mathrm{C}$ for 72 h. Total cellular lysates were prepared with RIPA lysis buffer (Bryotime, Shanghai, China), electrophoresed through a $10 \%$ SDS-polyacrylamide gel and then transferred onto nitrocellulose membranes (Bio-Rad, California, US) for examination of protein expression by Western blotting. A mouse anti-HIV-1 p24 antibody, mouse anti2G12 antibody, mouse anti-EGFP antibody and mouse anti- $\beta$-actin antibody were used as primary antibodies to identify HIV-1 gag, HIV gp145 and EGFP and $\beta$-actin proteins, respectively. HRP-conjugated goat anti-mouse $\lg \mathrm{G}$ was used as the secondary antibody. Proteins were 
Table 1 Primer sequences used for PCR and lengths of amplified fragment

\begin{tabular}{llc}
\hline Gene & Sequence $\left(5^{\prime}-3^{\prime}\right)$ & Length (bp) \\
\hline HIV-1 gag & F: CCATCGATGCCACCATGGGCGCCCGGGCC (Cal I) & 1503 \\
& R: CCTCTAGATTATTGTGACGAGGGT (Xba I) & \\
HIV gp145 & F: CCGCTAGCGCCACCATGAGAGTGACCGGCATC (Nhe I) & 2106 \\
& R: CCGTCGACTCACACGATGCTCAGCAC (Sal I) & \\
$T K$ & F: GGACGCGTATTGATTCACACCGTATTACAGAGG & 1006 \\
& R: CGCCCGGGTTCTCCTAATAAGTTACACCGTTTG & \\
$P 4 b$ & F: GGACGCGTCAGCAGGTGCTAAACAACAA & \\
& R: GGCTGCAGCGGTAGCTTAACGCCGAATA & 101 \\
EGFP & F: CATCTTCTTCAAGGACGACG & \\
& R: TGAAGTCGATGCCCTTCAG &
\end{tabular}

Restriction enzyme sites are underlined visualized with NBT and BCIP solutions. $\mathrm{rFPV}_{\mathrm{Hg}-\mathrm{Hp}}$ was identified in the same way. FPV-infected cells were used as negative controls, and $\beta$-actin served as the internal positive control.

HEK293 cells were infected with $\mathrm{rFPV}_{\mathrm{Hg}-\mathrm{Hp}}$ at the MOI of 5, and then expression levels of HIV-1 gag protein and HIV gp145 protein in a $\mathrm{rFPV}_{\mathrm{Hg}-\mathrm{Hp}}$-infected HEK293 cell layer were analyzed by Western blot.

\section{Growth Assays and Genetic Stability Analysis}

CEF cells were infected with FPV282E4 or $\mathrm{rFPV}_{\mathrm{Hg}-\mathrm{Hp}}$ at the MOI of 1. Virus-infected cells were collected and disrupted by ultrasonication at $12,24,36,48$ and 72 h postinfection (hpi). The virus titer was determined on CEF cells and represented as $\mathrm{TCID}_{50}$ values.

$\mathrm{rFPV}_{\mathrm{Hg}-\mathrm{Hp}}$ was passaged 20 times, and gDNA, RNA and total protein samples of the 1st, 5th, 10th, 15th and 20th passage in CEF cells were extracted. The genetic stability of HIV-1 gag and HIV gp145 genes was detected by PCR, RT-PCR and Western blot.

\section{Single Immunization of Mice}

Six-week-old BALB/c female mice (Experimental Animal Center, Academy of Military Medical Sciences of PLA, Beijing, China) were housed in an animal facility. Mice were divided into four experimental groups $(n=18)$. Group 1 was vaccinated with $1 \times 10^{7}$ plaque forming units (PFU) of $\mathrm{rFPV}_{\mathrm{Hg}-\mathrm{Hp}}$ in $100 \mu \mathrm{L}$ of PBS. Group 2 was vaccinated with $1 \times 10^{6} \mathrm{PFU}$ of $\mathrm{rFPV}_{\mathrm{Hg}-\mathrm{Hp}}$ in $100 \mu \mathrm{L}$ of PBS. Group 3 was vaccinated with $1 \times 10^{7}$ PFU of FPV282E4 in $100 \mu \mathrm{L}$ of PBS, and Group 4 was injected with $100 \mu \mathrm{L}$ of PBS. Blood samples were harvested on day 1, 7, 14, 21, 28 and 35, and serum samples were isolated and stored at $-80{ }^{\circ} \mathrm{C}$ for detecting HIV-1- and vector-specific antibodies by ELISA. Splenocytes were freshly collected at day 7 and 28 after the single immunization for the ELISPOT assay.

\section{Mouse Prime-Boost Immunization}

Mice were divided into four experimental groups $(n=24)$. The immunization dosage and route were the same as that for the single immunization experiment. The mice which were given a boost immunization were inoculated at day 21 after the prime vaccination. Blood samples were harvested at day $1,7,14,21,28,35,42$ and 49 , and then sera were obtained and stored at $-70{ }^{\circ} \mathrm{C}$ for further testing. Splenocytes were freshly collected at day 7 and 28 after prime-boost immunization for the ELISPOT assay.

\section{HIV-1- and Vector-Specific Antibody Detection by ELISA}

Levels of HIV-1- and vector-specific antibodies were measured by ELISA. HIV-1 p24 and gp120 protein (Immune Technology, Maryland, US) were employed as antigens, and sera from immunized mice as the primary antibody were 20-fold diluted in PBS. Peroxidase-conjugated goat anti-mouse $\operatorname{IgG}$ antibody, peroxidase-conjugated affinipure goat anti-mouse IgG1 or IgG2a antibody (diluted 1:1000 in PBS) as the secondary antibody was added to the appropriate wells and incubated at $37{ }^{\circ} \mathrm{C}$ for $2 \mathrm{~h}$. The optical density (OD) was detected at $492 \mathrm{~nm}$. A standard curve was constructed in the same conditions. FPV282E4 was coated with $1 \times 10^{6}$ PFU on 96-well microplates, and then vector-specific antibodies were detected in the same way.

\section{ELISPOT Analysis}

Peptide p24 (AMQMLKETI), peptide gp160 1 (VQCTHGIRPVVSTQL), $\quad$ peptide gp160 2 
(DTEVHNVWATHACVP), peptide gp160 3 (EQMHEDIISLWDQSL) and peptide gp160 4 (NVSTVQCTHGIRPVV) were used for stimulating splenocytes. IFN- $\gamma$ was evaluated with a Mouse IFN- $\gamma$ precoated ELISPOT kit (U-Cytech Bioscience, Utrencht, Netherlands) using procedures detailed in the operating manual.

\section{Statistical Analysis}

Statistical analysis and comparisons between immunization groups were performed using Graphpad Prism software 5.0 (San Diego, CA, USA). Differences with a $P$ value $<0.05$ or $<0.01$ were considered to be statistically significant. Data are presented as the mean \pm standard deviation (SD).

\section{Results}

\section{Construction and Identification of rFPV}

The rFPV shuttle vector pT3eGFP150-Hg-Hp was constructed as shown in Fig. 1a. The gag (1.5 kb) and gp145 $(2.1 \mathrm{~kb})$ genes could be digested by restriction enzymes to show that the plasmid pT3eGFP150-Hg-Hp had been constructed successfully (Fig. 1b).

The plasmid pT3eGFP150-Hg-Hp and 282E4 strain of FPV were co-transfected into $80 \%$ confluent CEF cells to select the $\mathrm{rFPV}_{\mathrm{Hg}-\mathrm{Hp} \text {-EGFP }}$ with $E G F P$ as the reporter gene. $\mathrm{rFPV}_{\mathrm{Hg}-\mathrm{Hp} \text {-EGFP }}$ expressing the target gene was obtained by 12 rounds of plaque screening. The reporter gene was then knocked out by using the Cre/Loxp system, and the $\mathrm{rFPV}_{\mathrm{Hg}-\mathrm{Hp}}$ without EGFP was also obtained by 12 rounds of plaque screening. The screening processes for $\mathrm{rFPV}$ are shown in Fig. 1c.

The gDNA and RNA of $\mathrm{rFPV}_{\mathrm{Hg}-\mathrm{Hp}-\mathrm{EGFP}}$ were identified by PCR and RT-PCR as shown in Fig. 1d. The HIV-1 gag (1533 bp), HIV gp145 (2106 bp) and P4b (578 bp) fragments could be amplified from the gDNA and cDNA of

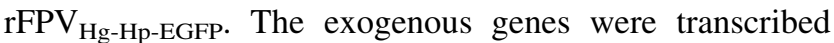

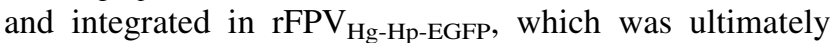
obtained when FPV-TK (1006 bp) could not be amplified by PCR. The expressed proteins were detected by Western blot as shown in Fig. 1f. The target proteins HIV-1 gag (55 kDa) and HIV gp145 (145 kDa) could be detected in

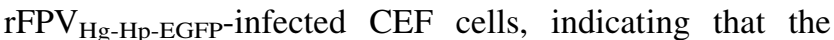
antigenic target proteins were expressed successfully.

The gDNA and RNA of $\mathrm{rFPV}_{\mathrm{Hg}-\mathrm{Hp}}$ were identified by PCR and RT-PCR as shown as Fig. 1e. The HIV-1 gag (1533 bp), HIV gpl45 (2106 bp) and TK (1006 bp) fragments could be amplified from gDNA and cDNA of $\mathrm{rFPV}_{\mathrm{Hg}-\mathrm{Hp}}$. The failure to amplify the EGFP (106 bp) gene by PCR showed that it was knocked out successfully, and the expression of target genes was not affected at the genomic and transcriptional levels by this procedure. The expressed proteins were detected by Western blot as shown in Fig. 1h. The target proteins HIV-1 gag ( $55 \mathrm{kDa})$ and HIV gp145 (145 kDa) could be detected in $\mathrm{rFPV}_{\mathrm{Hg}-\mathrm{Hp}}$-infected CEF cells. At the same time, the failure to detect the EGFP protein confirmed that the EGFP gene was knocked out successfully, and it had no effect on the expression of HIV-1 gag and HIV gp145 proteins at the translational level.

To evaluate whether $\mathrm{rFPV}_{\mathrm{Hg}-\mathrm{Hp}}$ could be expressed in mammalian cells, HEK293 cells were infected with $\mathrm{rFPV}_{\mathrm{Hg}-\mathrm{Hp}}$ at the MOI of 5 and stored at $37{ }^{\circ} \mathrm{C}$ with $5 \%$ $\mathrm{CO}_{2}$ for $72 \mathrm{~h}$. Examination by Western blot indicated that HIV-1 gag and HIV gp145 proteins were expressed in rFPV $_{\mathrm{Hg}-\mathrm{Hp}}$-infected HEK293 cells (Fig. 1g).

\section{Growth and Genetic Stability Analysis of rFPV}

Foreign exogenous genes were inserted into the FPV genome with the FPV shuttle vector pT3eGFP150-Hg-Hp by homologous recombination, causing the $T K$ gene to be blocked. Therefore, confirmation by transmission electron microscopy was necessary to determine whether the structure and morphogenesis of recombinant viruses were changed. Negatively stained virus particles of purified FPV282E4 and $\mathrm{rFPV}_{\mathrm{Hg}-\mathrm{Hp}}$ all possessed the characteristic morphology of mature poxviruses (Fig. 2a).

$\mathrm{rFPV}_{\mathrm{Hg}-\mathrm{Hp}}$ was continuously passaged 20 times, and the gDNA, RNA and total protein of the 1st, 5th, 10th, 15th and 20th passage in CEF cells were extracted. By PCR, RT-PCR and Western blot analysis, the HIV-1 gag and HIV gp145 genes showed good genetic stability in $\mathrm{rFPV}_{\mathrm{Hg}}$ Hp over at least 20 passages (Fig. 2b, c).

\section{Evaluation of HIV-1- and Vector-Specific Antibodies}

HIV-1 p24, HIV-1 gp120 and FPV282E4 which were inactivated at $65{ }^{\circ} \mathrm{C} 15$ min were employed as antigens and coated on 96-well microplates to measure levels of $\mathrm{IgG}$ antibodies in mouse sera by ELISA. The levels of HIV-1 p24-specific antibodies of $\mathrm{rFPV}_{\mathrm{Hg}-\mathrm{Hp}}$-immunized mice were not significantly elevated via a single immunization until the 35th day (Fig. 3b). While HIV-1-specific antibodies could not be stimulated through the single immunization, significantly elevated levels were observed in the $\operatorname{rFPV}_{\mathrm{Hg}-\mathrm{Hp}}\left(1 \times 10^{6} \mathrm{PFU}\right)$ group and other groups, which reached a peak of 8.5 -fold greater than that of the PBS group on the $28^{\text {th }}$ day after using prime-boost immunization $(P<0.01$, Fig. 4b). Levels of p24-specific IgG, IgG1 and IgG2a antibodies of the $\operatorname{rFPV}_{\mathrm{Hg}-\mathrm{Hp}}\left(1 \times 10^{6} \mathrm{PFU}\right)$ group were significantly higher than those of the other 


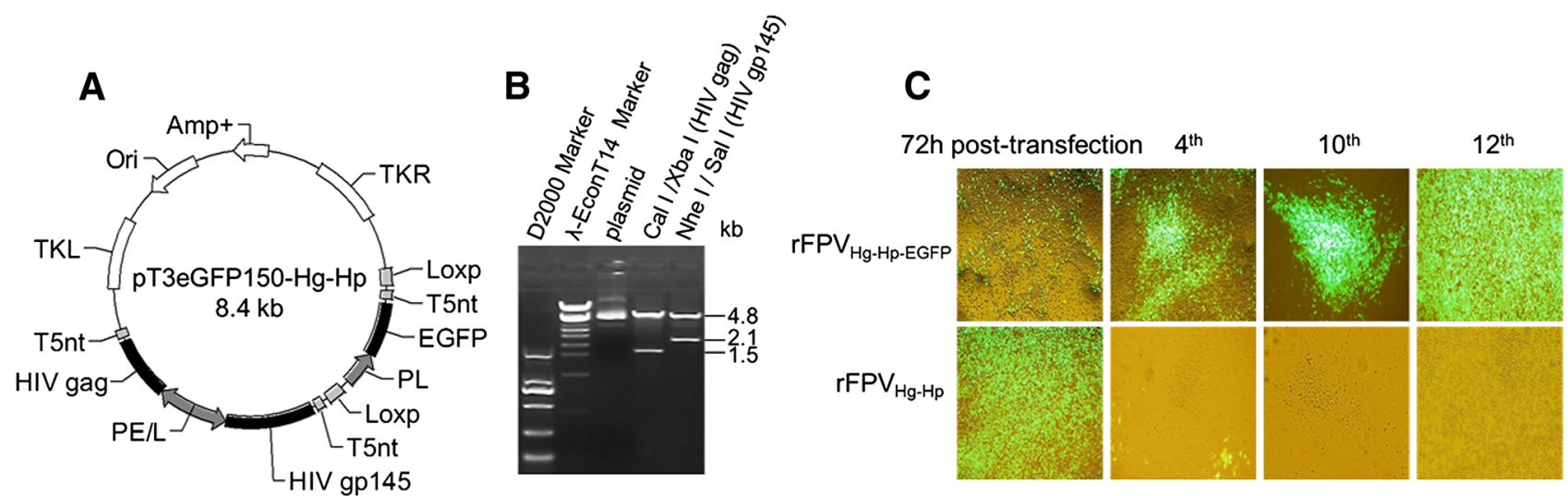

D

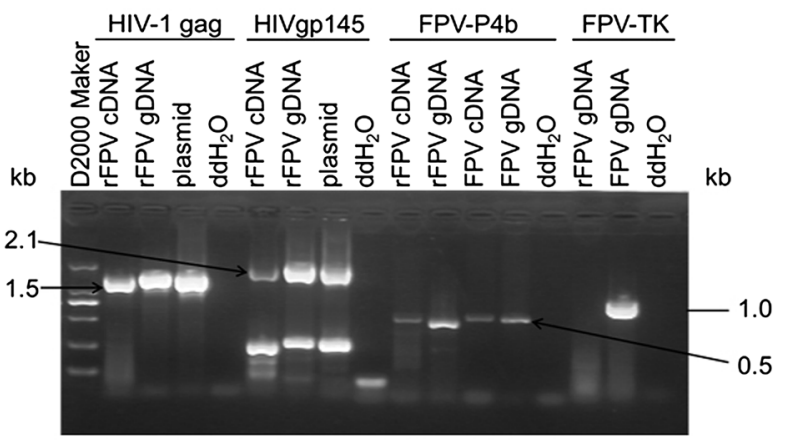

E

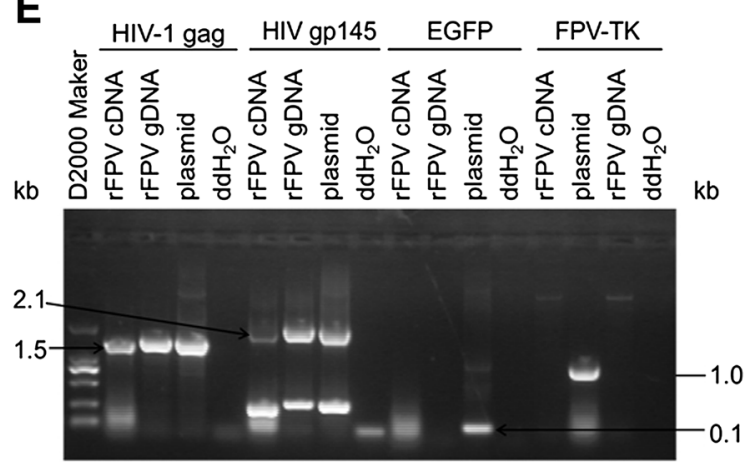

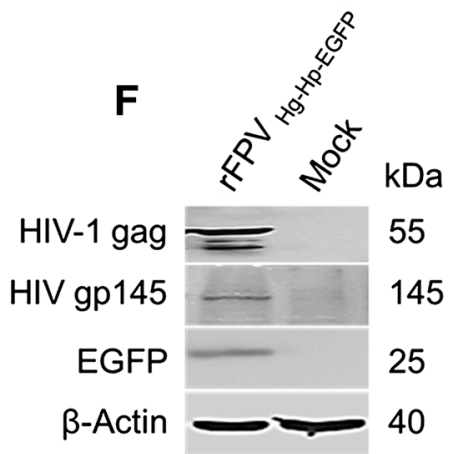

Fig. 1 Construction of rFPV plasmid co-expressing HIV-1 gag and gp145. a Schematic design of pT3eGFP-Hg-Hp; b identification of recombinant plasmid by enzyme digestion; c procedures for screening rFPV. Images represent results of $\mathrm{rFPV}_{\mathrm{Hg}-\mathrm{Hp}-\mathrm{EGFP}}$ and $\mathrm{rFPV}_{\mathrm{Hg}-\mathrm{Hp}}$ at $72 \mathrm{~h}$ post-transfection, as well as the 4th, 10th and 12th round of plaque screening; $\mathbf{d}$ identification of $\mathrm{rFPV}_{\mathrm{Hg} \text {-Hp-EGFP }}$ by PCR. The

groups $(P<0.05$, Fig. 4c, d). The IgG1 subtype was dominant in the immune response induced by the HIV-1 gag protein. The level of IgG antibodies specific for HIV-1 gp120 was not significantly different in the experimental groups and control groups, whether with a single immunization or prime-boost immunization (Figs. 3c, 4e). The level of vector-specific IgG antibody was raised on the 7 th day after the single immunization, but it was not significantly elevated from the 14th to 35 th day (Fig. 3d). Meanwhile, the level of vector-specific antibody which
$0.25 \mathrm{~kb}$ fragment which appeared in the analysis of the HIV gp145 gene was a non-specific fragment; e PCR analysis of $\mathrm{rFPV}_{\mathrm{Hg}-\mathrm{Hp}}$;

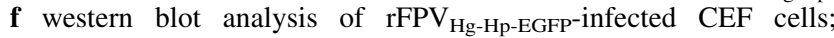
$\mathbf{h}$ western blot analysis of $\mathrm{rFPV}_{\mathrm{Hg}-\mathrm{Hp}}$-infected CEF cells; $\mathbf{g}$ western blot analysis of $\mathrm{rFPV}_{\mathrm{Hg}-\mathrm{Hp}}$-infected HEK293 cells

lasted until the 28th after boost immunization was unchanged in the prime-boost strategy (Fig. 4f).

\section{Measurements of HIV-1-Specific IFN- $\gamma$-Secreting Splenocytes}

Levels of IFN- $\gamma$-secreting cells of $\mathrm{rFPV}_{\mathrm{Hg}-\mathrm{Hp}}$-immunized mice were not significantly elevated at day 7 and 28 after a single immunization (Fig. 3e-h). While IFN- $\gamma$ secretion could not be stimulated through a single immunization, significant differences in the $\operatorname{rFPV}_{\mathrm{Hg}-\mathrm{Hp}}\left(1 \times 10^{6} \mathrm{PFU}\right)$ 
A

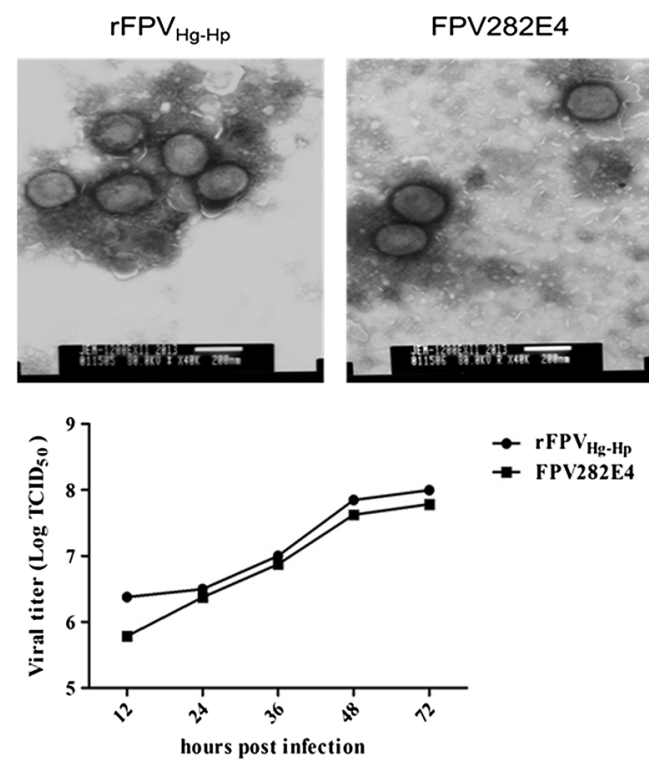

B
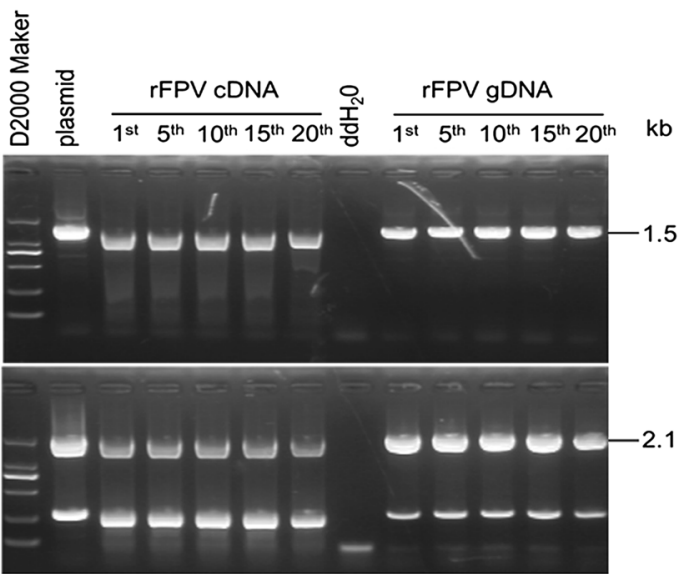

C

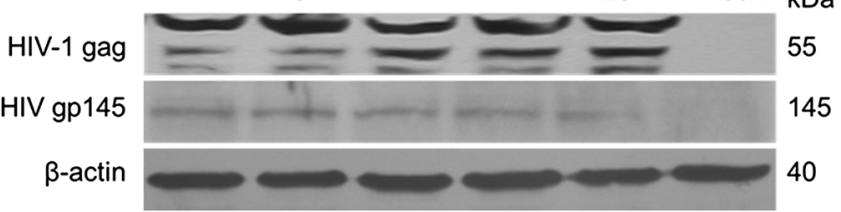

Fig. 2 Structural and genetic analyses of $\mathrm{rFPV}_{\mathrm{Hg}-\mathrm{Hp}}$. a Analysis of structure, morphogenesis and replication of $\mathrm{rFPV}_{\mathrm{Hg}-\mathrm{Hp}}$ compared with FPV282E4; $\mathbf{b}$, c genetic stability analysis of $\mathrm{rFPV}_{\mathrm{Hg}-\mathrm{Hp}}$. $\mathrm{rFPV}_{\mathrm{Hg}-\mathrm{Hp}}$ was passaged 20 times, and gDNA, RNA and total protein of the 1st,

group and other groups were observed at day 28 with the prime-boost immunization strategy $(P<0.05$, Fig. $4 \mathrm{~g}, \mathrm{j})$. The results showed that $\mathrm{HIV}-1$-specific IFN- $\gamma$-secreting cells were effectively generated by stimulation with peptide p24 (AMQMLKETI), peptide gp160 1 (VQCTHGIRPVVSTQL) and peptide gp160 2 (DTEVHNVWATHACVP). Thus, specific cell-mediated HIV-1 immune responses could be induced by $\mathrm{rFPV}_{\mathrm{Hg}-\mathrm{Hp}}$ $\left(10^{6} \mathrm{PFU}\right)$ through the prime-boost immunization strategy in $\mathrm{BALB} / \mathrm{c}$ mouse.

\section{Discussion}

The rFPV plasmid pT3eGFP150-Hg-Hp contains the EGFP gene, which could be specifically expressed in rFPV upon recombination. Such a reporter gene allowed for an intuitive screening process, and the optimum transfection conditions could be found simply through observing the frequency and intensity of green fluorescent cells. The screening cycle could then be shortened by adjusting the virus inoculation dose, infection time and plasmid transfection dose. The low recombinant rate led to a significantly lower rFPV yield compared to FPV. Therefore, in order to enhance the positive rate of rFPV, the virus inoculation dose was controlled until green fluorescence plaques were observed clearly. These plaques were then selected, and the virus inoculation dose was controlled to 5th, 10th, 15th and 20th passage in CEF cells were extracted to use for genetic stability analysis of HIV-1 gag and HIV gp145 genes by PCR, b RT-PCR and $\mathbf{c}$ western blot

reduce the positive rate of FPV. The FPPV $_{\mathrm{Hg}-\mathrm{Hp} \text {-EGFP }}$ could be identified when non-green fluorescent plaques were not observed, and $\mathrm{rFPV}_{\mathrm{Hg}-\mathrm{Hp}}$ could be detected until green fluorescence plaques were not observed using the same screening method.

The gag gene of HIV-1 subtype B was cloned from infected donors in Henan, China with the full-length sequence of $1503 \mathrm{bp}$. The HIV-1 gag protein size which was detected by an anti-p24 antibody was approximately $55 \mathrm{kDa}$. The HIV gp145 gene belonging to the HIV-1 B/C subtype in China is the membrane protein of the HIV-1 CN54 strain.

The main purpose of this study was to evaluate the immunogenicity of $\mathrm{rFPV}_{\mathrm{Hg}-\mathrm{Hp}}$. Therefore, measurements of HIV-1-specific antibodies and IFN- $\gamma$-secreting splenocytes were chosen to evaluate immune responses to the vaccine. As $\mathrm{rFPV}_{\mathrm{Hg}-\mathrm{Hp}}$ is a live-virus vaccine vector which itself can stimulate a strong immune response in the mouse model, we did not choose any other indexes to evaluate the immunogenicity of $\mathrm{rFPV}_{\mathrm{Hg}-\mathrm{Hp}}$. Other immune indices could have been used to study the immunogenicity of $\mathrm{rFPV}_{\mathrm{Hg}-\mathrm{Hp}}$, but they may be influenced by the vector nonspecifically and would not be good measures of the effects of the target proteins.

The results showed that HIV-1-specific antibodies and IFN- $\gamma$-secreting cells of $\mathrm{rFPV}_{\mathrm{Hg}-\mathrm{Hp}}$-immunized mice could not be induced via a single immunization, while they were effectively elicited by $\mathrm{rFPV}_{\mathrm{Hg}-\mathrm{Hp}}$ in a prime-boost 


\section{A}

Single immunization

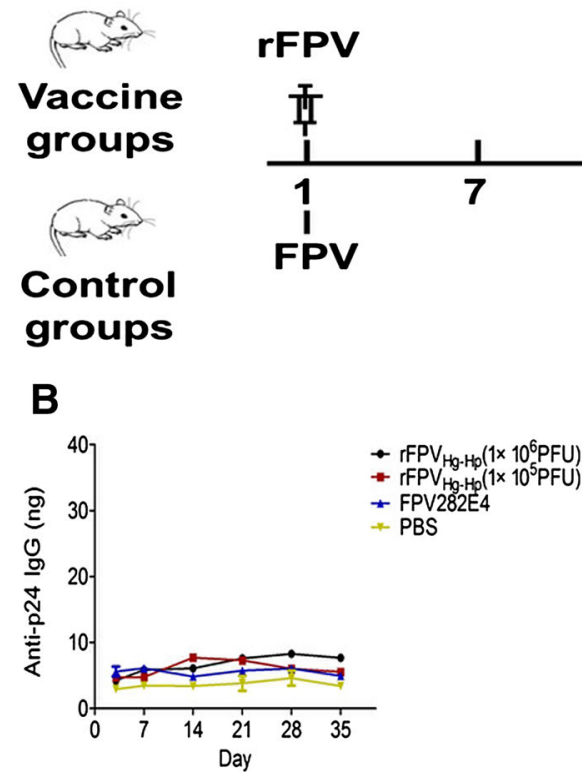

C
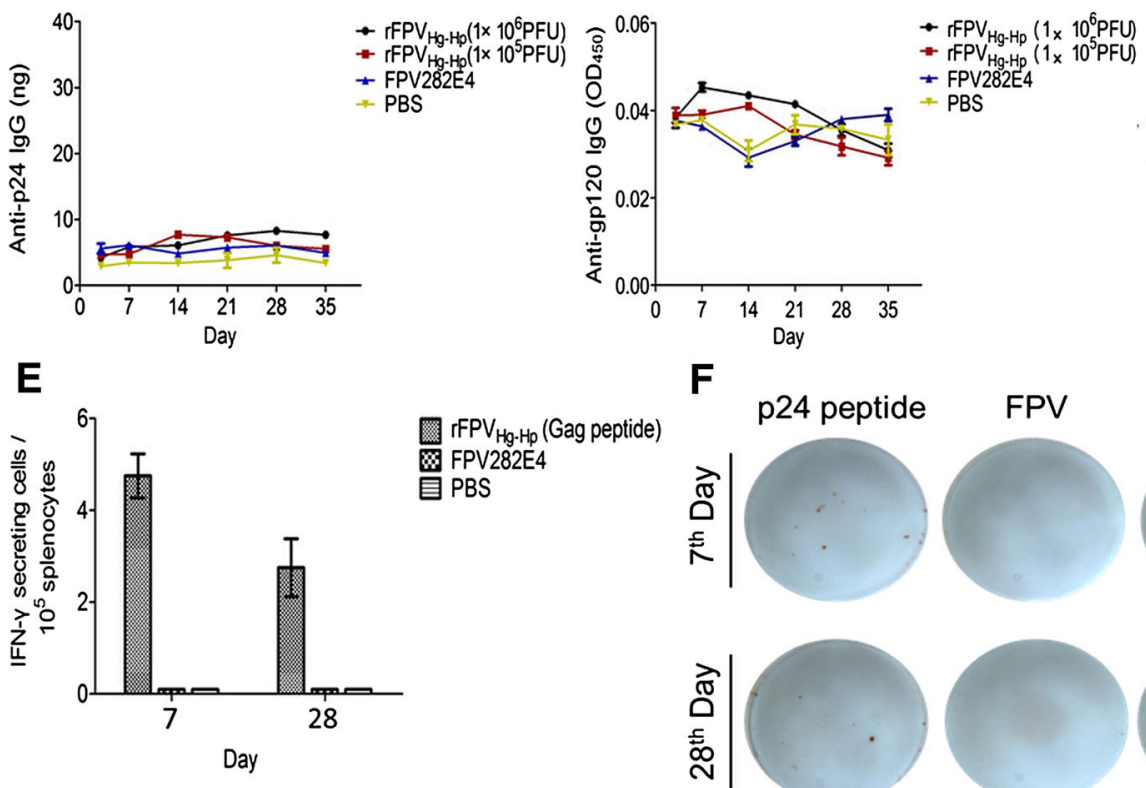

D

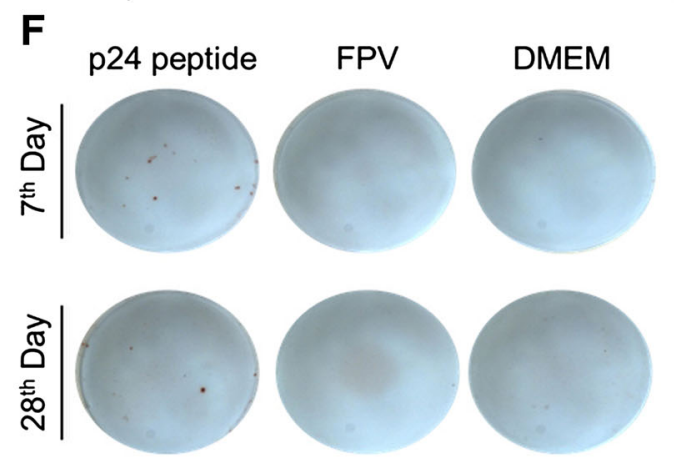

G

H
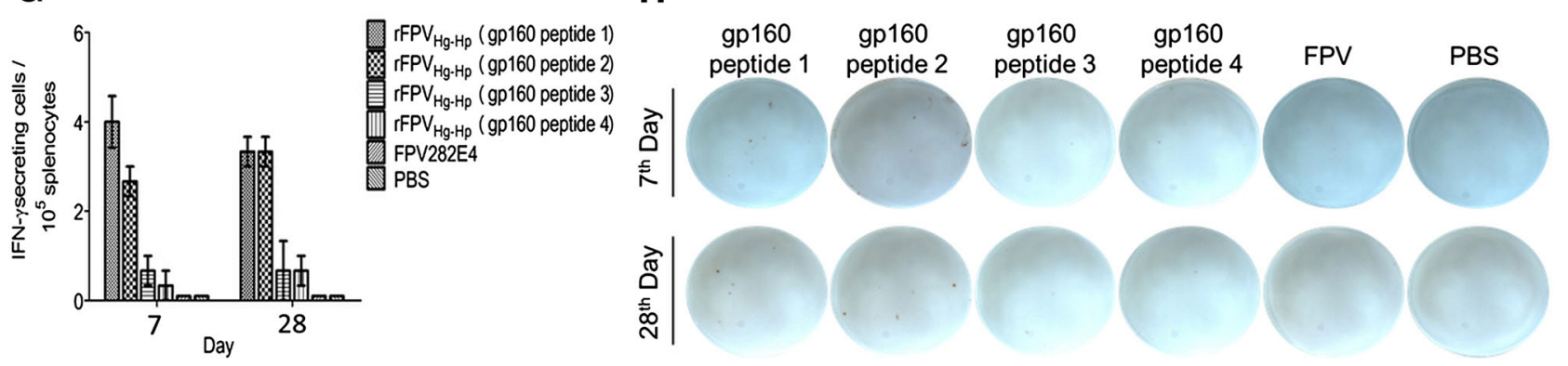

Fig. 3 Evaluation of antibody and cellular immune responses to single immunization with $\mathrm{rFPV}_{\mathrm{Hg}-\mathrm{Hp}}$. a Immunological strategy; b HIV-1 p24-specific IgG, c HIV-1 gp120-specific IgG and d vectorspecific antibody levels were evaluated by ELISA after a single

immunization; cellular immune responses were quantified using an IFN- $\gamma$-based ELISPOT assay by stimulating splenocytes at the e 7 th and $\mathbf{g} 28$ th day after the single immunization; $\mathbf{f}, \mathbf{h}$ graphical diagrams of ELISPOT results

immunization strategy. The IgG1 antibody level was slightly higher than that of the IgG2a antibody, suggesting that the IgG1 subtype was dominant in the HIV-1 gag protein-elicited immune responses. Although the optimized HIV gp145 protein based on Env retained most of the epitopes, it was lowly expressed and could not sufficiently induce the generation of specific antibodies to be detected

by ELISA. Alternatively, the HIV-1 gp145 protein-specific antibodies induced may not have been able to bind to the HIV-1 gp120 antigen. These reasons may explain why HIV-1 gp120 as the coating antigen could not be used to completely evaluate the level of HIV-1 specific antibodies induced by the HIV gp145 protein. 

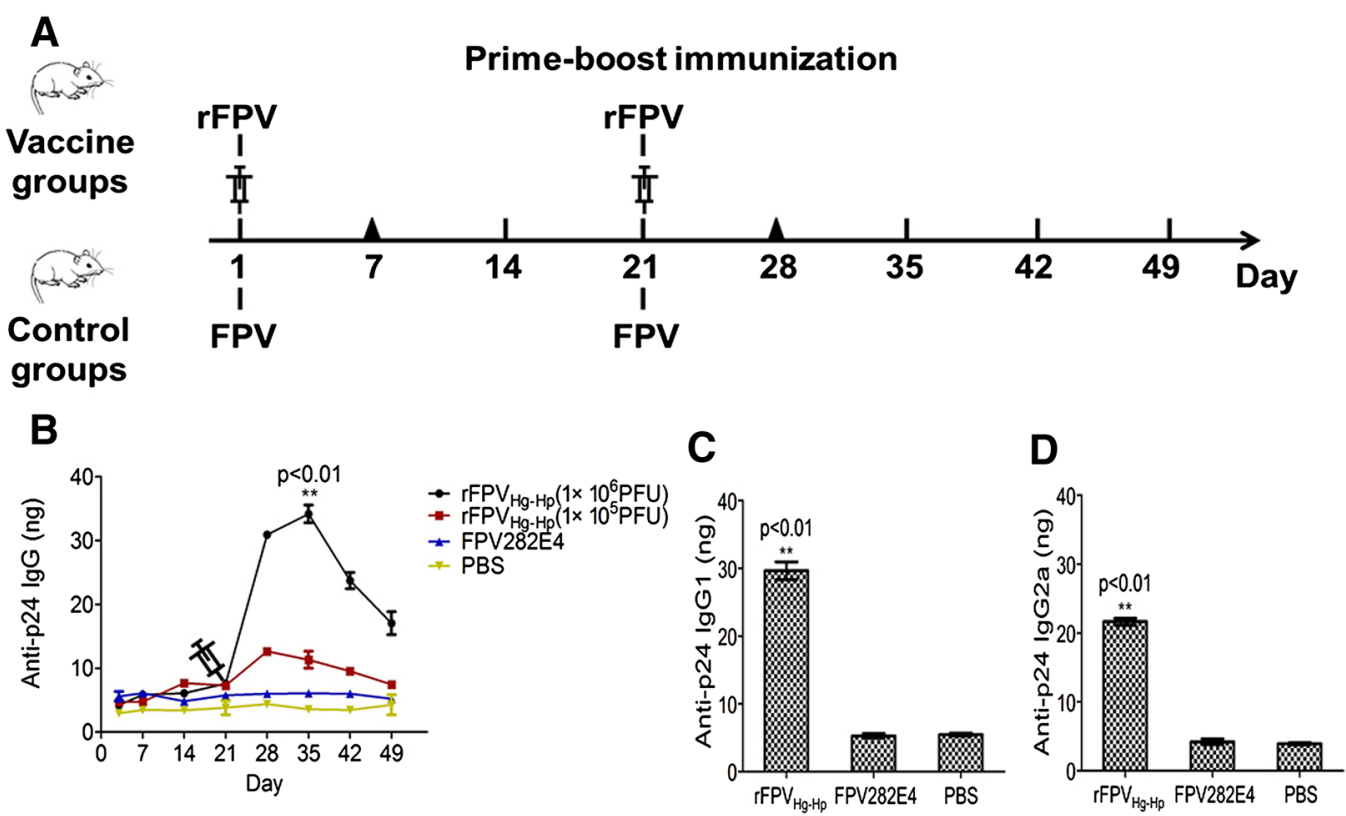

E

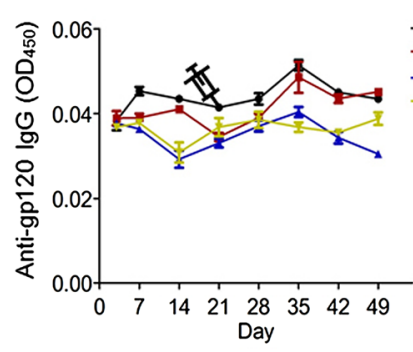

G
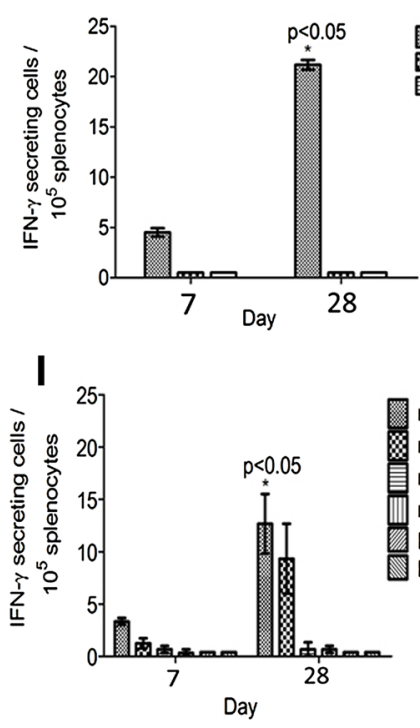

$\mathbf{F}$
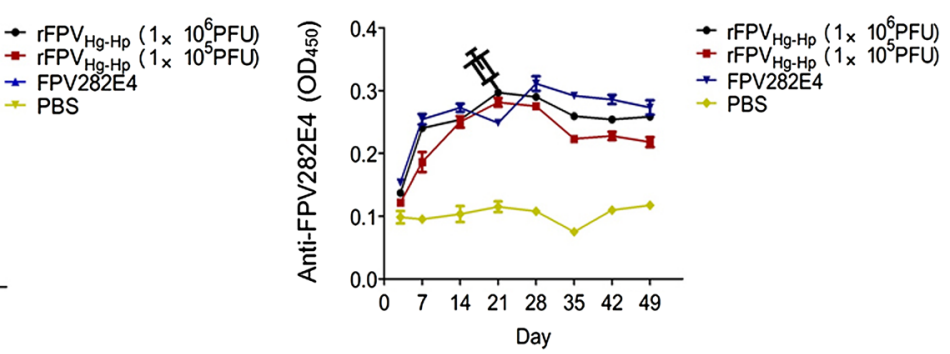

H
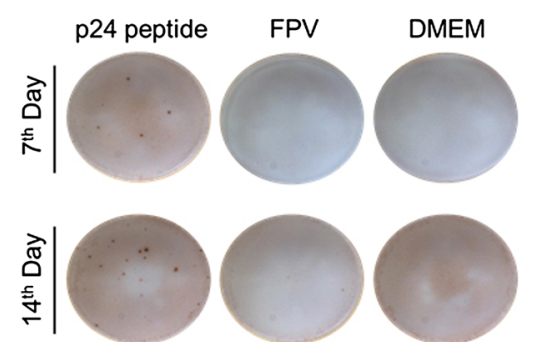

rFPV ${ }_{\text {Hg-Hp }}$ (gp160 peptide 1) rFPV $\mathrm{Hg}_{\mathrm{Hp}}$ ( gp160 peptide 2) rFPV ${ }_{\mathrm{Hg}-\mathrm{Hp}}$ (gp160 peptide 3) rFPV ${ }_{\text {Hg-Hp }}$ ( gp160 peptide 4) FPV282E4 PBS

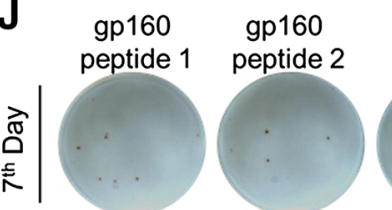

gp160

peptide 3

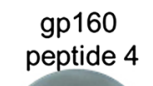

FPV PBS
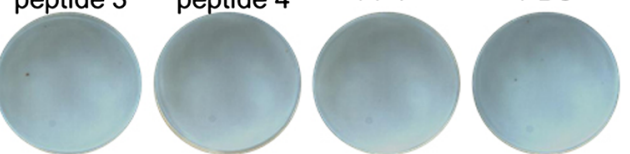

㳮
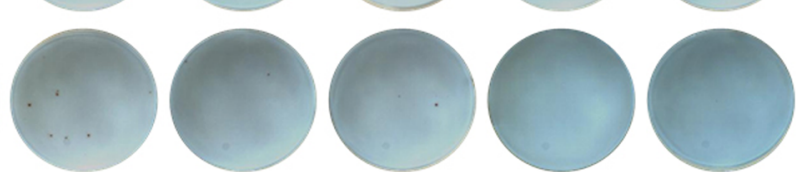

Fig. 4 Evaluation of antibody and cellular immune responses to prime-boost immunization with $\mathrm{rFPV}_{\mathrm{Hg}-\mathrm{Hp} \text {. }}$ a Immunological strategy; b HIV-1 p24-specific IgG, e HIV-1 gp120-specific IgG and f vector-specific antibody levels were evaluated by ELISA after prime-boost immunization; c The p24-specific $\operatorname{IgG1}$ and d IgG2a

levels of the $\mathrm{rFPV}_{\mathrm{Hg}-\mathrm{Hp}}\left(10^{6} \mathrm{PFU}\right)$ group on the 14 th day after boost immunization; Cellular immune responses were quantified with IFN$\gamma$-based ELISPOT assays by stimulating splenocytes on the $\mathbf{g} 7$ th and i 28th day in the prime-boost immunization strategy. $\mathbf{h}, \mathbf{j}$ Graphical diagrams of ELISPOT results 
While high levels of HIV-1 specific antibodies were elicited by $\mathrm{rFPV}_{\mathrm{Hg}-\mathrm{Hp}}$, it also strongly induced a vectorspecific humoral immune response at the same time. The results indicated that the FPV vector-based vaccine could be used for a repeat vaccination at least once. However, its use in combination with antiretroviral drugs or other vaccines would be best for treating and preventing HIV.

Although high levels of HIV-1-specific antibodies and IFN- $\gamma$-secreting cells were shown to be effectively induced by $\mathrm{rFPV}_{\mathrm{Hg}-\mathrm{Hp}}$ in this study, the immunogenicity and safety of $\mathrm{rFPV}_{\mathrm{Hg}-\mathrm{Hp}}$ will need to be further studied in order to determine whether the antibodies that it induces can effectively prevent HIV-1 infection. Other experiments to enhance immunogenicity and evaluate its safety will need to be designed. Nevertheless, this work demonstrates the good immunogenicity of $\mathrm{rFPV}_{\mathrm{Hg}-\mathrm{Hp}}$ and provides a foundation for subsequent empirical studies on this candidate vaccine against HIV-1.

Acknowledgements This work was financially supported by Grants from the National Naturel Science Foundation of China (No. 31472197) and the National Mega Project on Major Infectious Diseases Prevention (No. 2012ZX10001005-006).

\section{References}

1. Qiao C, Yu K, Jiang Y, Li C, Tian G, Wang X, Chen H (2006) Development of a recombinant fowlpox virus vector-based vaccine of H5N1 subtype avian influenza. Dev Biol 124:127-132

2. Chen HY, Shang YH, Yao HX, Cui BA, Zhang HY, Wang ZX, Wang YD, Chao AJ, Duan TY (2011) Immune responses of chickens inoculated with a recombinant fowlpox vaccine coexpressing HA of H9N2 avain influenza virus and chicken IL-18. Antivir Res 91:50-56. doi:10.1016/j.antiviral.2011.04.007

3. Pitisuttithum P, Rerks-Ngarm S, Bussaratid V, Dhitavat J, Maekanantawat W, Pungpak S, Suntharasamai P, Vanijanonta S, Nitayapan S, Kaewkungwal J, Benenson M, Morgan P, O’Connell RJ, Berenberg J, Gurunathan S, Francis DP, Paris R, Chiu J, Stablein D, Michael NL, Excler JL, Robb ML, Kim JH (2011) Safety and reactogenicity of canarypox ALVAC-HIV (vCP1521) and HIV-1 gp120 AIDSVAX B/E vaccination in an efficacy trial in Thailand. PLoS ONE 6:e27837. doi:10.1371/journal.pone. 0027837

4. Novitsky V, Rybak N, McLane MF, Gilbert P, Chigwedere P, Klein I, Gaolekwe S, Chang SY, Peter T, Thior I, Ndung'u T, Vannberg F, Foley BT, Marlink R, Lee TH, Essex M (2001) Identification of human immunodeficiency virus type 1 subtype $\mathrm{C}$ Gag-, Tat-, Rev-, and Nef-specific elispot-based cytotoxic T-lymphocyte responses for AIDS vaccine design. J Virol 75:9210-9228. doi:10.1128/JVI.75.19.9210-9228.2001

5. Williamson C, Morris L, Maughan MF, Ping LH, Dryga SA, Thomas R, Reap EA, Cilliers T, van Harmelen J, Pascual A, Ramjee G, Gray G, Johnston R, Karim SA, Swanstrom R (2003) Characterization and selection of HIV-1 subtype C isolates for use in vaccine development. AIDS Res Hum Retrovir 19:133-144. doi:10.1089/088922203762688649

6. Garrod TJ, Gargett T, Yu W, Major L, Burrell CJ, Wesselingh S, Suhrbier A, Grubor-Bauk B, Gowans EJ (2014) Loss of long term protection with the inclusion of HIV pol to a DNA vaccine encoding gag. Virus Res 192:25-33. doi:10.1016/j.virusres.2014. 08.008

7. Buseyne F, Le Chenadec J, Corre B, Porrot F, Burgard M, Rouzioux C, Blanche S, Mayaux MJ, Riviere Y (2002) Inverse correlation between memory Gag-specific cytotoxic T lymphocytes and viral replication in human immunodeficiency virusinfected children. J Infect Dis 186:1589-1596. doi:10.1086/ 345482

8. Gupta SB, Mast CT, Wolfe ND, Novitsky V, Dubey SA, Kallas EG, Schechter M, Mbewe B, Vardas E, Pitisuttithum P, Burke D, Freed D, Mogg R, Coplan PM, Condra JH, Long RS, Anderson K, Casimiro DR, Shiver JW, Straus WL (2006) Cross-clade reactivity of HIV-1-specific T-cell responses in HIV-1-infected individuals from Botswana and Cameroon. J Acquir Immune Defic Syndr 42:135-139. doi:10.1097/01.qai.0000223017.01568. e7

9. Turnbull EL, Lopes AR, Jones NA, Cornforth D, Newton P, Aldam D, Pellegrino P, Turner J, Williams I, Wilson CM, Goepfert PA, Maini MK, Borrow P (2006) HIV-1 epitopespecific $\mathrm{CD} 8+\mathrm{T}$ cell responses strongly associated with delayed disease progression cross-recognize epitope variants efficiently. J Immunol 176:6130-6146

10. Kulkarni V, Rosati M, Valentin A, Ganneru B, Singh AK, Yan J, Rolland M, Alicea C, Beach RK, Zhang GM, Le Gall S, Broderick KE, Sardesai NY, Heckerman D, Mothe B, Brander C, Weiner DB, Mullins JI, Pavlakis GN, Felber BK (2013) HIV-1 p24(gag) derived conserved element DNA vaccine increases the breadth of immune response in mice. PLoS ONE 8:e60245. doi:10.1371/journal.pone.0060245

11. Zhou J, Cheung AK, Tan Z, Wang H, Yu W, Du Y, Kang Y, Lu $X$, Liu L, Yuen KY, Chen Z (2013) PD1-based DNA vaccine amplifies HIV-1 GAG-specific CD8+ T cells in mice. J Clin Investig 123:2629-2642. doi:10.1172/JCI64704

12. Chakrabarti BK, Kong WP, Wu BY, Yang ZY, Friborg J, Ling X, King SR, Montefiori DC, Nabel GJ (2002) Modifications of the human immunodeficiency virus envelope glycoprotein enhance immunogenicity for genetic immunization. J Virol 76:5357-5368

13. Wieczorek L, Krebs SJ, Kalyanaraman V, Whitney S, Tovanabutra S, Moscoso CG, Sanders-Buell E, Williams C, Slike B, Molnar S, Dussupt V, Alam SM, Chenine AL, Tong T, Hill EL, Liao HX, Hoelscher M, Maboko L, Zolla-Pazner S, Haynes BF, Pensiero M, McCutchan F, Malek-Salehi S, Cheng RH, Robb ML, VanCott T, Michael NL, Marovich MA, Alving CR, Matyas GR, Rao M, Polonis VR (2015) Comparable antigenicity and immunogenicity of oligomeric forms of a novel, acute HIV-1 subtype C gp145 envelope for use in preclinical and clinical vaccine research. J Virol 89:7478-7493. doi:10.1128/JVI.0041215

14. Du S, Liu C, Zhu Y, Wang Y, Ren D, Wang M, Tan P, Li X, Tian M, Zhang Y, Li J, Zhao F, Li C, Jin N (2015) Construction and characterization of novel fowlpox virus shuttle vectors. Virus Res 197:59-66. doi:10.1016/j.virusres.2014.12.015

15. Amano H, Morikawa S, Shimizu H, Shoji I, Kurosawa D, Matsuura Y, Miyamura T, Ueda Y (1999) Identification of the canarypox virus thymidine kinase gene and insertion of foreign genes. Virology 256:280-290. doi:10.1006/viro.1999.9648

16. Huw Lee L, Hwa Lee K (1997) Application of the polymerase chain reaction for the diagnosis of fowl poxvirus infection. J Virol Methods 63:113-119

17. Scheiflinger F, Falkner FG, Dorner F (1997) Role of the fowlpox virus thymidine kinase gene for the growth of FPV recombinants in cell culture. Arch Virol 142:2421-2431 